\title{
Low Temperature Infrared Spectroscopy Study of Pyrazinamide: From the Isolated Monomer to the Stable Low Temperature Crystalline Phase
}

\author{
Ana Borba, ${ }^{\dagger}$ Merwe Albrecht, ${ }^{\ddagger}$ Andrea Gómez-Zavaglia, ${ }^{\dagger}{ }^{\dagger}$ Martin A. Suhm, ${ }^{\ddagger}$ and Rui Fausto ${ }^{*}, \dagger$ \\ Department of Chemistry, University of Coimbra, Portugal, Institute for Physical Chemistry, University of \\ Göttingen, Germany, and Centro de Investigación y Desarrollo en Criotecnología de Alimentos, (Conicet La \\ Plata, UNLP) RA-1900, Argentina
}

Received: August 03, 2009; Revised Manuscript Received: October 02, 2009

\begin{abstract}
A structural and spectroscopic analysis of the anti-tuberculosis drug pyrazinamide (PZA) was carried out. The PZA molecule was predicted theoretically to possess two conformers differing by internal rotation around the $\mathrm{C}-\mathrm{C}(=\mathrm{O})$ bond, with the $E$ conformer $\left(C_{\mathrm{s}}\right.$ symmetry point group; $\mathrm{N}-\mathrm{C}-\mathrm{C}=\mathrm{O}$ dihedral: $\left.180^{\circ}\right)$ being ca. $30 \mathrm{~kJ} \mathrm{~mol}^{-1}$ more stable than the $Z$ form $\left(C_{1}\right.$ point group; $\mathrm{N}-\mathrm{C}-\mathrm{C}=\mathrm{O}$ dihedral: ca. $\left.\pm 42^{\circ}\right)$. In consonance with both the large energy difference and low energy barrier between the $Z$ and $E$ conformers, upon isolation in low temperature argon and xenon matrices, only the $E$ form could be observed and characterized spectroscopically. In the argon matrix, this conformer was found to exist in at least three matrix sites, of different stability. In a supersonic jet, besides the monomer $(E)$, the most stable dimer of PZA with two equivalent $\mathrm{NH} \cdots \mathrm{O}=$ hydrogen bonds could also be identified. Its spectrum reveals rapid energy flow out of the excited NH stretching mode mediated by one of the heteroatoms in the ring. Finally, the IR spectra of the amorphous solid resulting from fast cooling of the vapor of the compound (initially in the $\alpha$ crystalline phase) onto the cold substrate of the cryostat $(10 \mathrm{~K})$ and of the crystalline phase resulting from warming the amorphous solid were also recorded and interpreted. The obtained crystalline phase was found to be the thermodynamically most stable $\delta$ polymorph of PZA.
\end{abstract}

\section{Introduction}

Pyrazinamide (pyrazine-2-carboxamide, abbreviated here as PZA; Figure 1) is an important first line drug used for the treatment of Mycobacterium tuberculosis ${ }^{1-3}$ in combination with other drugs, such as isoniazid (recently studied by $\mathrm{us}^{4}$ ) and rifampicin.

Because of its pharmacological relevance, several analytical methods have been reported for the determination of PZA in pure and dosage forms and in biological fluids. In this sense, there are several studies in the literature dealing with the vibrational and NMR properties of the compound and of several of its molecular complexes. ${ }^{3,5-13}$ Surprisingly, most of these studies ignored the fact that the crystalline compound may exist in several polymorphic forms. Indeed, PZA was found to crystallize in at least four different polymorphs $(\alpha, \beta, \delta, \gamma$; a fifth form, $\alpha^{\prime}$, very similar to form $\alpha$, has also been proposed; see Figure 2). ${ }^{14-17}$ This tendency to form different polymorphs can be ascribed mainly to the existence of several H-bond donor/ acceptor groups in the PZA molecule but also to the presence of the aromatic ring, both contributing to give the compound the possibility to establish many different relevant intermolecular interactions.

The crystal structure of the first PZA polymorphic form to be studied ( $\alpha$-phase) was determined first by Takaki et al. in $1959^{18}$ and subsequently refined by the same authors 1 year later. ${ }^{19}$ Other authors have further studied this crystal later on. ${ }^{20-22}$ The $\beta$-PZA polymorph was first investigated by Ro and Sorum. $^{23}$ These two forms ( $\alpha$ and $\beta$ ), as well as the $\delta$

\footnotetext{
* Corresponding author. E-mail: rfausto@ci.uc.pt.

${ }^{\dagger}$ University of Coimbra.

* University of Göttingen.

${ }^{\S}$ Centro de Investigación y Desarrollo en Criotecnología de Alimentos.
}

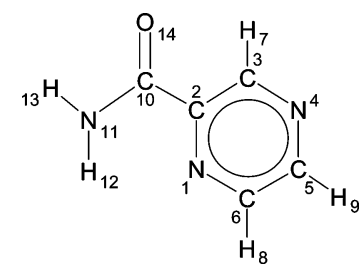

Figure 1. Schematic representation of the molecule of PZA with adopted atom numbering.

modification (whose structure was also determined in 1972 by Ro and Sorum ${ }^{24}$ ), show relatively small structural differences, having the same dimeric unit as the main structural motif of the crystal and differing essentially in their secondary hydrogen bond interactions (see Figure 2). The $\gamma$ polymorphic variety, on the other hand, is substantially different from the other polymorphs in relation with the hydrogen bond topology. Its structure was obtained only in 1987 by Nakata and Takaki ${ }^{25}$ by X-ray diffraction, after the initial efforts of Tamura and Kuwano $^{26}$ (IR spectroscopy) and Takaki, ${ }^{27}$ who obtained preliminary information on the crystal structure of $\gamma$-PZA using an ellipsoid-model approach.

The fact that most of the previously reported solid state spectroscopic studies on PZA had ignored the polymorphism exhibited by this compound strongly reduces their significance. For example, infrared or Raman data for the compound have been discussed in several of those studies ${ }^{3,6,8,10,11,28-30}$ without specification of which polymorph was under investigation. In a recent study, Castro et al. ${ }^{31}$ reported the infrared spectra of the different polymorphs of PZA, thus filling an important gap on the available knowledge about this compound. Taking the conclusions of that study into account, it can now be stated beyond doubt that Gunasekaran and Sailatha, ${ }^{3}$ Akyuz and 

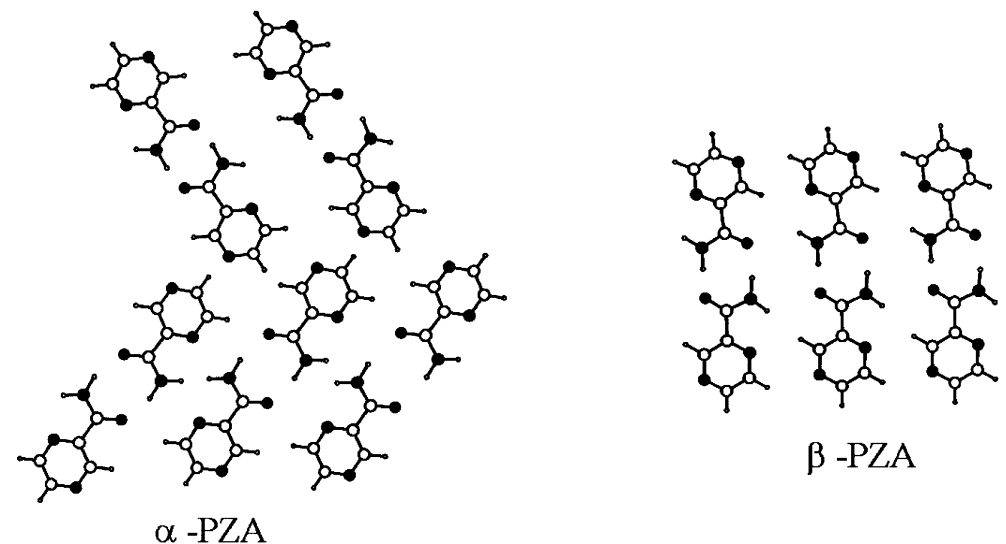

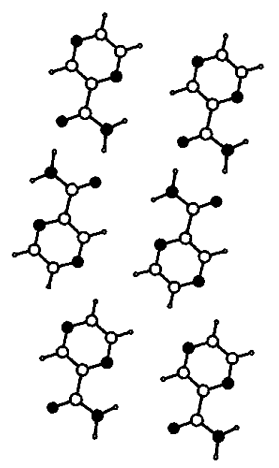

$\delta$-PZA

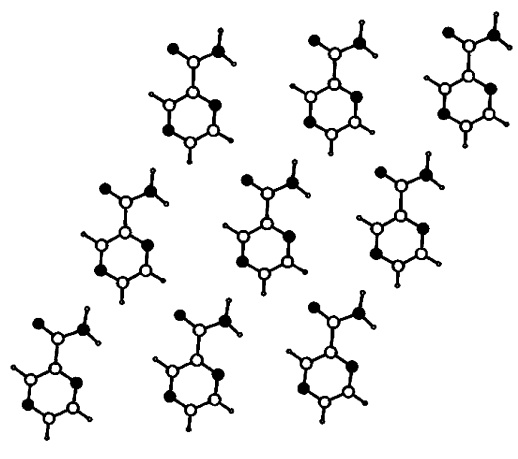

$\gamma-\mathrm{PZA}$

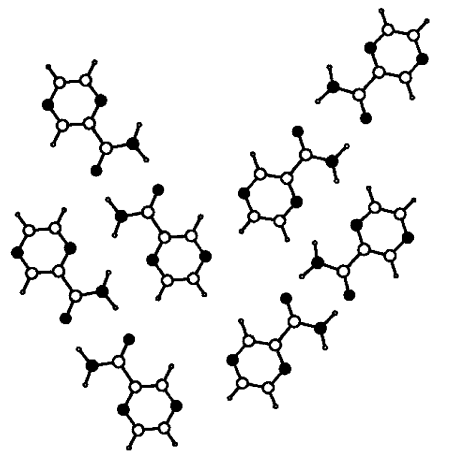

$\alpha^{\prime}-\mathrm{PZA}$

Figure 2. Schematic representation of the $\alpha, \beta, \delta$, and $\gamma$ polymorphs of PZA and of the not yet confirmed possible fifth polymorph, $\alpha^{\prime}$ (adapted from ref 14).

Akyuz, ${ }^{8}$ Favila et al., ${ }^{28}$ Cozar et al., ${ }^{29}$ and Chiş et al. ${ }^{30}$ investigated the $\alpha$ polymorph, whereas Kalkar et al. ${ }^{6}$ studied $\alpha$-PZA in nujol mull but the $\gamma$ polymorph in $\mathrm{KBr}$ pellet; Wang et al. ${ }^{11}$ presented data of poor quality, but probably all corresponding to the $\gamma$ polymorph. According to Castro et al., ${ }^{31}$ all polymorphs are kinetically stable at room temperature, with the $\gamma$ form being the stable polymorph above $180^{\circ} \mathrm{C}$ and the $\delta$ one being the most stable polymorph at low temperature.

In contrast with the substantial number of studies previously reported on the crystalline states of PZA, no experimental data on the isolated molecule have been reported hitherto. Theoretically, ${ }^{28-30}$ two possible conformers of PZA have been predicted to exist, one with the $\mathrm{NH}_{2}$ group in the cis position to the ring nitrogen atom ortho to the amide substituent ( $E$ conformer) and the other one with the $\mathrm{NH}_{2}$ group in the trans position ( $\mathrm{Z}$ conformer). According to the theoretical predictions, ${ }^{29,30}$ conformer $E$ has a planar structure, while in the second conformer the plane containing the $\mathrm{C}_{2}, \mathrm{C}_{10}, \mathrm{~N}_{11}$, and $\mathrm{O}_{14}$ atoms remains $33.8^{\circ}$ out of the pyrazinic ring and the $\mathrm{H}_{12}$ and $\mathrm{H}_{13}$ atoms are twisted 25.6 and $6.5^{\circ}$ in relation to the $\mathrm{C}_{2} \mathrm{C}_{10} \mathrm{~N}_{11} \mathrm{O}_{14}$ plane. The $E$ conformer was predicted to be $34.9 \mathrm{~kJ} \mathrm{~mol}^{-1}$ more stable than the $Z$ form. ${ }^{29,30}$ The isolated centrosymmetric dimer based on the $E$ monomer that constitutes the main structural motif of the $\alpha, \beta$, and $\delta$ crystalline modifications of PZA has also been studied theoretically. ${ }^{29,30}$ It was suggested that the two $\mathrm{N}-\mathrm{H} \cdots \mathrm{O}=$ intermolecular H-bonds in this dimer are moderately strong and predominately electrostatic in nature, following the general pattern found for dimers of other compounds formed by $\mathrm{N}-\mathrm{H} \cdots \mathrm{O}=$ bonds. $^{30}$ All the previously reported theoretical studies on $\mathrm{PZA}^{28-30}$ used density functional theory (DFT) based methods with basis sets of different sizes.

In the present study, we performed a detailed investigation of the potential energy surface of both the monomer and dimer
TABLE 1: Total $(E)$ and Relative $(\Delta E)$ Energies (Including Zero Point Vibrational Contributions) for PZA Conformers ${ }^{a}$

\begin{tabular}{ccrrrr}
\hline & \multicolumn{2}{c}{ B3LYP/6-311++G(d,p) } & & \multicolumn{2}{c}{ MP2/6-31G $(\mathrm{d}, \mathrm{p})^{b}$} \\
\cline { 2 - 3 } \cline { 5 - 6 } conformer & \multicolumn{1}{c}{$E$} & $\Delta E$ & & \multicolumn{1}{c}{$E$} & \multicolumn{1}{c}{$\Delta E$} \\
\hline$E$ & -1136971.0 & 0.0 & & -1133416.0 & 0.0 \\
$Z$ & -1136938.3 & 32.7 & & -1133384.6 & 31.4
\end{tabular}

${ }^{a}$ Energies in $\mathrm{kJ} \mathrm{mol}^{-1}$; conformers are depicted in Figure 3. ${ }^{b}$ MP2 energies were corrected by zero point energies obtained at the B3LYP/6-311++G(d,p) level of theory.

of PZA, using both density functional theory (B3LYP) and (for the monomers) correlated $a b$ initio (second-order Møller-Plesset) methods. The theoretical results were used to help interpreting the infrared spectra of the compound in various experimental conditions, within the $10-298 \mathrm{~K}$ temperature range: matrix isolated (in both argon and xenon matrices; monomeric PZA), in a supersonic jet (monomer and dimer), and in the low temperature amorphous and crystalline neat solid phases resulting from deposition of the vapor of the compound onto the cryostat substrate kept at $10 \mathrm{~K}$ and at temperatures up to $298 \mathrm{~K}$ due to subsequent warming. As described below, the crystalline phase obtained in this way was found to be the thermodynamically most stable $\delta$ polymorph of PZA, in contrast to the starting material used, that corresponded to the commercially available $\alpha$ polymorph.

\section{Experimental and Computational Methods}

Infrared Spectroscopy. PZA was obtained from Fluka $(\alpha-$ form, purity $\geq 99 \%$ ). The low temperature matrices were prepared by codeposition of the isolating gas (argon N60 or xenon N45, both obtained from Air Liquide) and PZA sublimate, 
a)

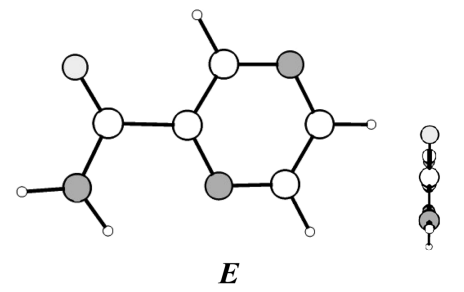

$\mathrm{C}_{\mathrm{S}}\left(180^{\circ}\right)|\mu|=4.0 \mathrm{D}$

b)

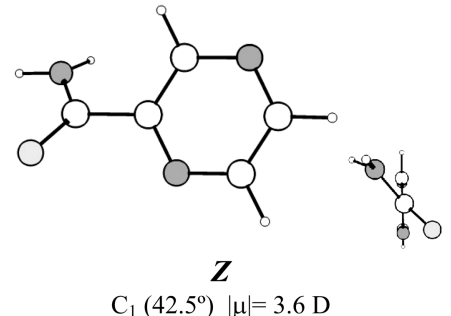

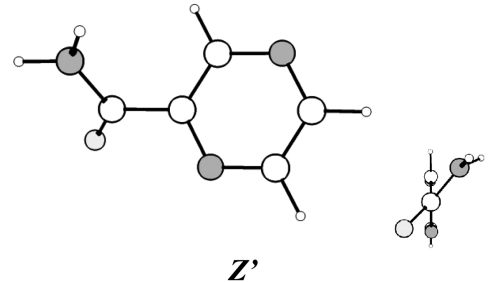

$\mathrm{C}_{1}\left(-42.5^{\circ}\right)|\mu|=3.6 \mathrm{D}$

Figure 3. DFT(B3LYP)/6-311++G(d,p) optimized structures and dipole moments of the conformers of PZA. Two perspectives are provided, one with the viewpoint placed above the ring (left) and the other with the viewpoint along the major axis of the molecule. The $\mathrm{N}_{11}-\mathrm{C}_{10}-\mathrm{C}_{2}-\mathrm{C}_{3}$ dihedral angle is indicated in parentheses.
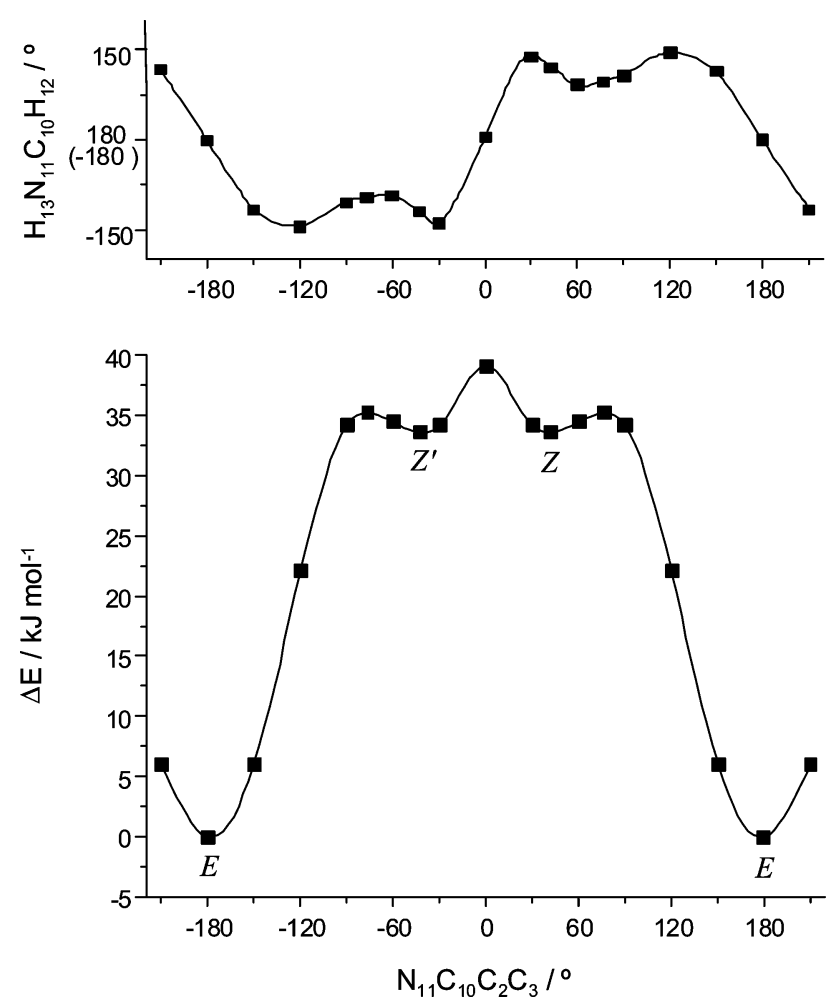

Figure 4. Calculated DFT(B3LYP)/6-311++G(d,p) potential energy profile for internal rotation around the $\mathrm{C}_{10}-\mathrm{C}_{2}$ bond of PZA and change of pyramidalization at the amide nitrogen atom along this rotation (as measured by the $\mathrm{H}-\mathrm{N}(-\mathrm{C})-\mathrm{H}$ dihedral angle).

in an approximately 1000:1 concentration ratio, onto the cooled CsI substrate of the cryostat (APD Cryogenics closed-cycle helium refrigeration system with a DE-202A expander). The compound was placed in a specially designed temperature variable mini-oven assembled inside the cryostat. The temperature of the mini-oven used to evaporate the compound was, in all experiments, ca. $40{ }^{\circ} \mathrm{C}$, as measured in situ by means of a thermopair connected to a digital temperature controller (homemade). The solid film of the neat compound was prepared in a way similar to that used to obtain the matrices, but in this case only vapors of the compound were deposited onto the CsI substrate of the cryostat and the evaporation temperature was

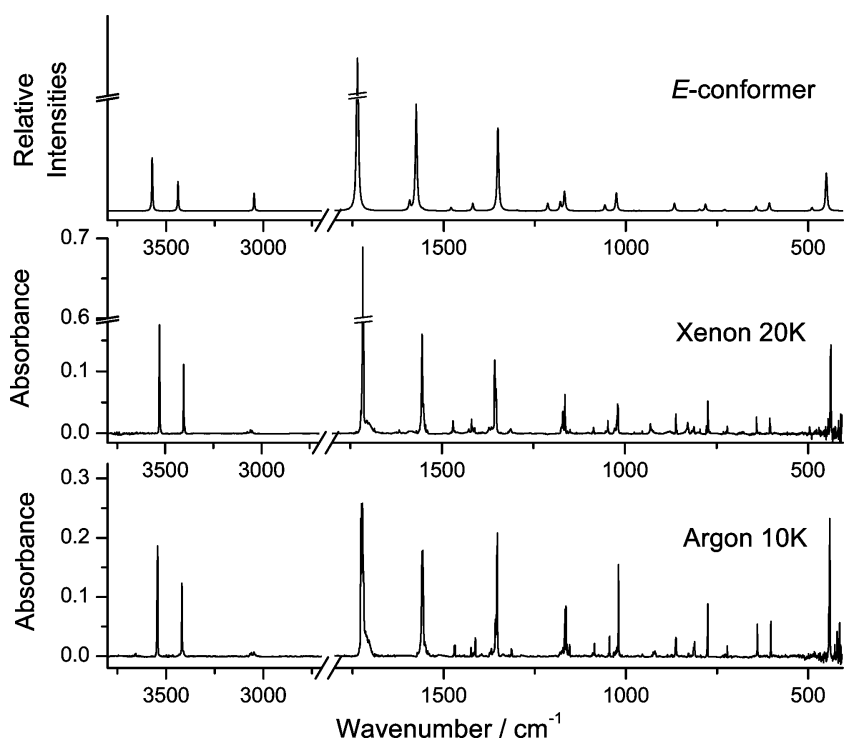

Figure 5. Experimental infrared spectra $\left(4000-500 \mathrm{~cm}^{-1}\right.$ spectral range) of PZA in argon $(10 \mathrm{~K})$ and xenon $(20 \mathrm{~K})$ matrices and B3LYP/ $6-311++\mathrm{G}(\mathrm{d}, \mathrm{p})$ calculated spectrum for the most stable conformer $(E)$. The calculated spectrum was simulated using Lorentzian functions with full width at half-maximum of $5 \mathrm{~cm}^{-1}$, with wavenumbers being scaled by 0.960 in the high frequency range and 0.988 below $1800 \mathrm{~cm}^{-1}$.

ca. $100{ }^{\circ} \mathrm{C}$, since in these experiments a larger flux of the compound can be used. In the annealing experiments, the temperature was controlled and measured using a Scientific Instruments digital temperature controller with a silicon diode sensor (model 9659 ) to within $\pm 1^{\circ}$. The temperature variation during the annealing was done in steps of $2^{\circ}$ in the matrix isolation experiments and $10-20^{\circ}$ in the studies on the neat solid compound.

The matrix isolation and low temperature neat solid sample IR spectra were collected, with $0.5 \mathrm{~cm}^{-1}$ spectral resolution, on a Nicolet 6700 Fourier transform infrared (FTIR) spectrometer equipped with a deuterated triglycine sulfate (DTGS) detector and a $\mathrm{Ge} / \mathrm{KBr}$ beam splitter.

In the pulsed supersonic jet FTIR spectroscopic studies, the expansion from a double slit nozzle of $10 \times 0.5 \mathrm{~mm}^{2}$ cross section (heatable design ${ }^{32,33}$ ) was probed in direct absorption by a focused FTIR beam. Reference spectra without expansion 
TABLE 2: Observed Wavenumbers for the Matrix Isolated PZA Monomer with Band Assignments ${ }^{a}$

\begin{tabular}{|c|c|c|c|c|}
\hline \multirow{2}{*}{$\begin{array}{l}\text { approximate } \\
\text { description }\end{array}$} & \multirow{2}{*}{$\begin{array}{c}\text { calculated } \\
\text { wavenumber }\end{array}$} & \multirow{2}{*}{$\begin{array}{l}\text { calculated } \\
\text { intensity }\end{array}$} & \multicolumn{2}{|c|}{ observed wavenumber } \\
\hline & & & argon matrix $(10 \mathrm{~K})$ & xenon matrix $(20 \mathrm{~K})$ \\
\hline$v\left(\mathrm{NH}_{2}\right)$ as & 3570.9 & 89.5 & $\begin{array}{l}3548(-) / 3545(+) / \\
3543(-)\end{array}$ & 3530 \\
\hline$v\left(\mathrm{NH}_{2}\right) \mathrm{s}$ & 3438.5 & 49.6 & 3418 & 3404 \\
\hline$v(\mathrm{C}-\mathrm{H}) 1$ & 3070.8 & 0.2 & $\begin{array}{l}3069(-) / 3065(+) / \\
3061(+)\end{array}$ & 3075 \\
\hline$v(\mathrm{C}-\mathrm{H}) 3$ & 3047.3 & 30.1 & $3048(-) / 3041(-)$ & 3058 \\
\hline$v \operatorname{ring} 5$ & 1593.8 & 15.3 & 1573 & 1570 \\
\hline$\delta\left(\mathrm{NH}_{2}\right)$ & 1575.6 & 179.9 & $1560(-) / 1557(+)$ & 1554 \\
\hline$v$ ring 2 & 1558.0 & 1.5 & 1552 & 1551 \\
\hline$\delta(\mathrm{C}-\mathrm{H}) 3$ & 1479.7 & 5.6 & $1471(+) / 1469(-)$ & 1470 \\
\hline$\delta(\mathrm{C}-\mathrm{H}) 2$ & 1420.2 & 12.5 & $1430 / 1425 / 1420 / 1417 / 1415 / 1413$ & $1429 / 1427 / 1419 / 1417 / 1413 / 1411$ \\
\hline$v$ ring 1 & 1168.6 & 32.7 & $\begin{array}{l}1168(-) / 1167(+) / 1165(-) / \\
1162(-)\end{array}$ & 1164 \\
\hline $\mathrm{w}\left(\mathrm{NH}_{2}\right)$ & 1078.4 & 0.1 & $1091 / 1086$ & $1089 / 1086$ \\
\hline$v$ ring 6 & 1057.7 & 9.8 & 1045 & 1047 \\
\hline$\delta$ ring 1 & 1026.4 & 30.3 & $1028 / 1025 / 1021 / 1017$ & $1028 / 1023 / 1022 / 1020 / 1019$ \\
\hline$\gamma(\mathrm{C}-\mathrm{H}) 2$ & 978.4 & 0.5 & 955 & 953 \\
\hline$\gamma(\mathrm{C}-\mathrm{H}) 1$ & 963.6 & 0.6 & $925(+) / 921(-)$ & $931 / 927 / 923$ \\
\hline$\gamma(\mathrm{C}-\mathrm{H}) 3$ & 867.3 & 12.9 & $\begin{array}{l}866(-) / 865(-) / 864(+) / \\
863(+) / 862(-)\end{array}$ & $861 / 860 / 858$ \\
\hline$\delta$ ring 2 & 798.1 & 2.6 & $815(+) / 812(-)$ & 812 \\
\hline$\gamma(\mathrm{C}=\mathrm{O})$ & 781.8 & 11.4 & $777(-) / 776(-)$ & $778 / 774$ \\
\hline$\tau$ ring 1 & 729.3 & 2.4 & 722 & 721 \\
\hline$\delta$ ring 3 & 642.8 & 7.3 & 639 & 641 \\
\hline$\tau$ ring 3 & 149.9 & 0.4 & n.i. & n.i. \\
\hline$\tau(\mathrm{C}-\mathrm{C})$ & 70.7 & 1.0 & n.i. & n.i. \\
\hline
\end{tabular}

${ }^{a} \mathrm{~B} 3 \mathrm{LYP} / 6-311++\mathrm{G}(\mathrm{d}, \mathrm{p})$ calculated spectrum for conformer $E$ is also given. Wavenumbers (scaled by 0.960 in the high frequency range and 0.988 below $1800 \mathrm{~cm}^{-1}$ ) in $\mathrm{cm}^{-1}$, calculated intensities in $\mathrm{km} \mathrm{mol}^{-1} . \nu$, bond stretching; $\delta$, bending; $\gamma$, rocking; $\tau$, torsion; w, wagging; tw, twisting; s, symmetric; as, antisymmetric; $(+)$, most stable site; $(-)$, less stable sites; n.i., not investigated.

$\left(I_{0}\right.$, vacuum) were collected immediately before the gas pulse and used to determine the absorbance, $\ln \left(I_{0} / I\right)$, from the expansion spectra $(I)$. The buildup of background pressure in the pulsed jet experiments was limited by a $4 \mathrm{~m}^{3}$ stainless steel vacuum chamber followed by a $250 \mathrm{~m}^{3} \mathrm{~h}^{-1}$ pumping system and by up to $40 \mathrm{~s}$ pumping intervals between pulses. Typically, data from one hundred to several hundred gas pulses were coadded for the IR spectra shown in this work. Gas pulses were controlled by magnetic valves. PZA was adsorbed on a dried molecular sieve and seeded into the He (99.996\%, Air Liquide) carrier gas by flowing the gas at 1-2 bar through a heated (to $140{ }^{\circ} \mathrm{C}$ ) reservoir containing the molecular sieve. For further details on the experimental setup, see refs 32 and 33. The FTIR signal (Bruker IFS 66v) was detected by a large area InSb or MCT detector equipped with an appropriate optical filter. The spectral resolution was $2 \mathrm{~cm}^{-1}$.

Computational Methodology. The quantum chemical calculations were performed with the Gaussian 03 suite of programs $^{34}$ at the DFT/B3LYP ${ }^{35-37}$ and (in the case of monomers) MP2 levels of theory, using the $6-311++\mathrm{G}(\mathrm{d}, \mathrm{p})$ and $6-31 G(d, p)$ basis sets, respectively. ${ }^{38}$ Structures were optimized using the geometry direct inversion of the invariant subspace (GDIIS) method, ${ }^{39}$ with the nature of the obtained stationary points being checked by inspection of the corresponding Hessian matrix.

The DFT(B3LYP)/6-311++G(d,p) calculated vibrational frequencies were scaled by 0.960 in the $\mathrm{N}-\mathrm{H}$ and $\mathrm{C}-\mathrm{H}$ stretching regions and 0.988 for all the remaining spectral regions, and used to assist the interpretation of the experimentally observed spectra. ${ }^{40}$ Normal coordinate analyses were undertaken in the internal coordinate space as described by Schachtschneider and Mortimer ${ }^{41}$ using a locally modified version of the program BALGA and the optimized geometries and harmonic force constants resulting from the DFT calculations. Potential energy profiles for internal rotation were calculated by performing a relaxed scan on the DFT(B3LYP)/ $6-311++G(d, p)$ potential energy surface along the relevant coordinates, and the transition state structures for conformational interconversion were obtained using the synchronous transitguided quasi-Newton (STQN) method. ${ }^{42}$ 

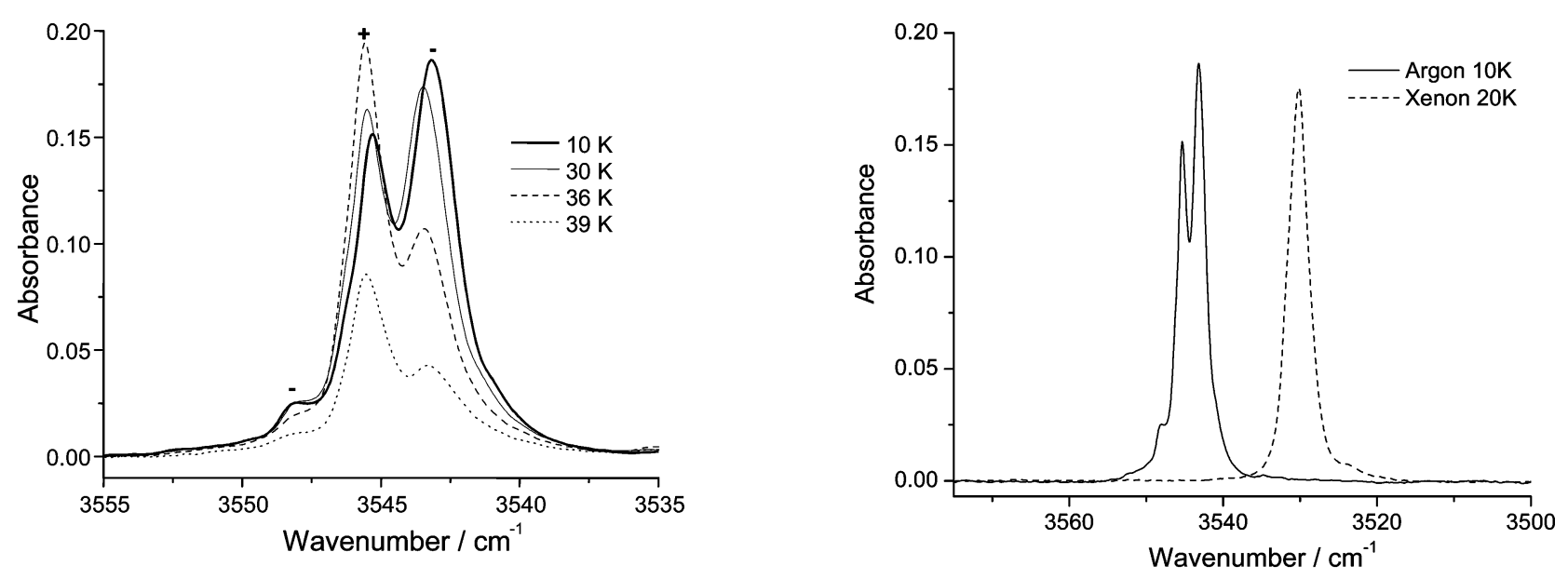

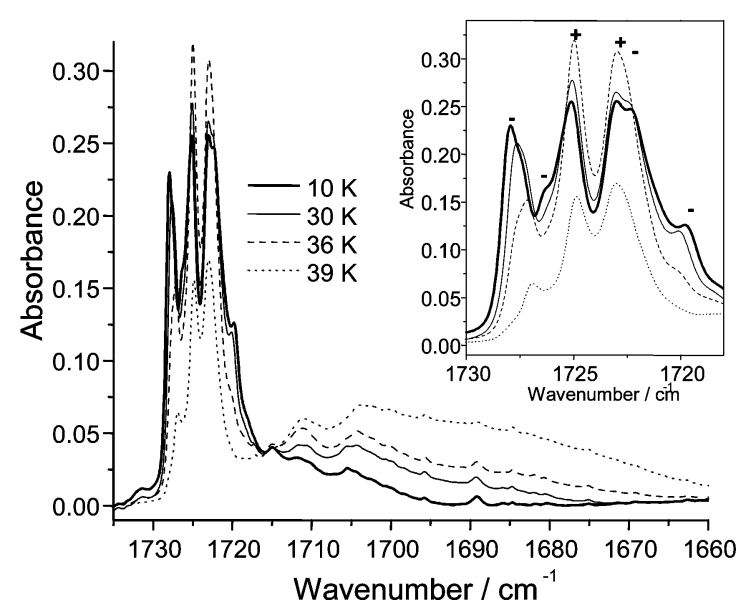

Figure 6. Infrared spectra (3555-3535 and $1735-1660 \mathrm{~cm}^{-1}$ regions) of PZA trapped in argon at $10 \mathrm{~K}$ (bold solid line) and after annealing at $30 \mathrm{~K}$ (thin solid line), $36 \mathrm{~K}$ (dashed), and $39 \mathrm{~K}$ (dotted). The (+) and $(-)$ indicate bands due to the PZA monomer in the more and two less stable matrix sites, respectively.

\section{Results and Discussion}

Geometries and Energies. The conformationally relevant internal rotational axis in PZA is defined by the $\mathrm{N}_{11}-\mathrm{C}_{10}-\mathrm{C}_{2}-\mathrm{C}_{3}$ dihedral angle. Table 1 displays the calculated relative energies of the two conformers obtained at the B3LYP/ $6-311++\mathrm{G}(\mathrm{d}, \mathrm{p})$ and MP2/6-31G(d,p) levels of theory and including zero point corrections (Figure 3 ). The corresponding optimized geometrical parameters are provided in Table S1 in the Supporting Information.

In agreement with the previous studies, ${ }^{29,30}$ the most stable conformer $(E)$ was predicted to be planar $\left(C_{\mathrm{s}}\right.$ point group) at both levels of theory used in the present study. This conformer is stabilized by the presence of two weak intramolecular H-bond type interactions $\left(\mathrm{N}_{11} \mathrm{H}_{12} \cdots \mathrm{N}_{1}\right.$ and $\mathrm{C}_{3}-\mathrm{H}_{7} \cdots \mathrm{O}_{14}$, with H-bond distances of 2.29 and $2.55 \AA$, respectively) and predicted to be ca. $30 \mathrm{~kJ} \mathrm{~mol}^{-1}$ more stable than conformer $Z$ (see Table 1). Conformer $Z$ is nonplanar (two enantiomeric forms: $Z$ and $Z$; see Figure 3) and belongs to the $C_{1}$ symmetry point group, with the $\mathrm{N}_{11}-\mathrm{C}_{10}-\mathrm{C}_{2}-\mathrm{C}_{3}$ dihedral angle being equal to $\pm 42.5^{\circ}$ (B3LYP; $\pm 39.3^{\circ}$, when calculated at the MP2 level) and the amide nitrogen atom pyramidalized [the $\mathrm{H}-\mathrm{N}(-\mathrm{C})-\mathrm{H}$ dihedral angle is calculated to be $156.0^{\circ}$ and $146.5^{\circ}$ at DFT and MP2 levels of theory, respectively].

The higher stability of conformer $E$ is mainly due to the presence of the two intramolecular H-bond-like interactions, which stabilize the molecule in a planar arrangement. In contrast,

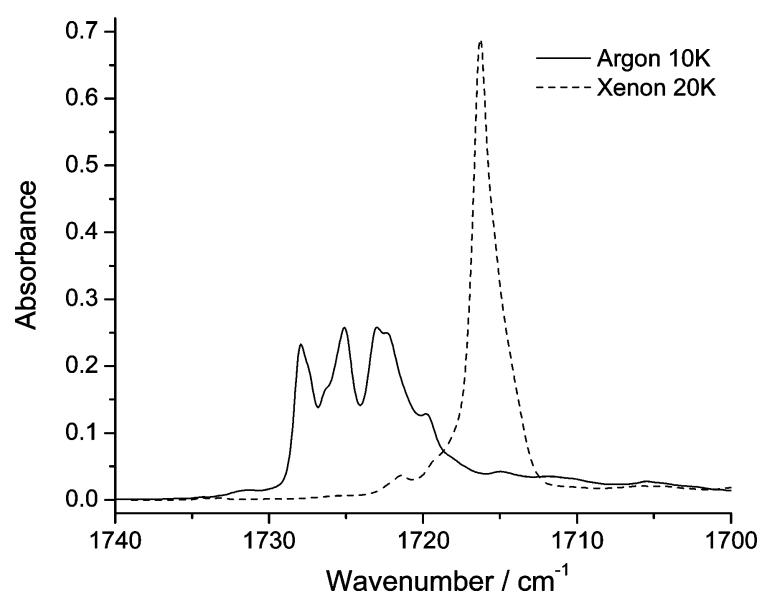

Figure 7. Selected spectral regions of the infrared spectra of PZA trapped in argon (solid line) and xenon (dashed line) matrices, showing the occurrence of matrix site splitting in argon. Top panel: $\mathrm{N}-\mathrm{H}$ asymmetric stretching (three bands in argon; one single band in xenon). Bottom: $\mathrm{C}=\mathrm{O}$ stretching (six overlapping bands in argon; one asymmetric band corresponding to an unresolved pair of bands in xenon).

conformer $Z$ is nonplanar mainly due to the repulsion between the $\mathrm{O}_{14}$ and $\mathrm{N}_{1}$ lone pairs and between $\mathrm{H}_{12}$ and $\mathrm{H}_{7}$ (see Figure 3).

Figure 4 shows the B3LYP/6-311++G(d,p) potential energy profile associated with the internal rotation around the $\mathrm{C}_{10}-\mathrm{C}_{2}$ bond, corresponding to the interconversion pathways relating the two different conformers of PZA and the two enantiomeric forms of conformer $Z$. The $Z \rightarrow Z$ energy barrier was found to be $5.6 \mathrm{~kJ} \mathrm{~mol}^{-1}$, whereas the energy barrier separating conformer $Z$ from conformer $E$ was predicted to be only $1.7 \mathrm{~kJ} \mathrm{~mol}^{-1}(35.2$ $\mathrm{kJ} \mathrm{mol}^{-1}$ in the reverse direction). The variation of the pyramidalization at the amide nitrogen along the rotation around the $\mathrm{C}_{10}-\mathrm{C}_{2}$ bond, as measured by the $\mathrm{H}-\mathrm{N}(-\mathrm{C})-\mathrm{H}$ dihedral angle, is also shown in Figure 4. It reveals a compromise between three factors: steric repulsions between the $\mathrm{O}_{14}$ and $\mathrm{N}_{1}$ lone pairs and between $\mathrm{H}_{12}$ and $\mathrm{H}_{7}$, which favor pyramidalization, mesomerism within the amide group, which favors a trigonal nitrogen, and, for structures close to the global minimum, the trend to attain a more favorable geometry for the establishment of the intramolecular $\mathrm{N}_{11}-\mathrm{H}_{12} \cdots \mathrm{N}_{1}$ and $\mathrm{C}_{3}-\mathrm{H}_{7} \cdots \mathrm{O}_{14} \mathrm{H}$-bond type interactions. As for the $E$ conformer, the transition state for interconversion between the two symmetry-equivalent $Z$ forms has a trigonal nitrogen. In this conformation, the $\mathrm{N}_{11}-\mathrm{C}_{10}-\mathrm{C}_{2}-\mathrm{C}_{3}$ dihedral is $0^{\circ}$ and the $\mathrm{N}$ and $\mathrm{O}$ atoms are vis-à-vis, as well as $\mathrm{H}_{12}$ and $\mathrm{H}_{7}$. The reduction of energy is accompanied by pyramidalization at the amide 

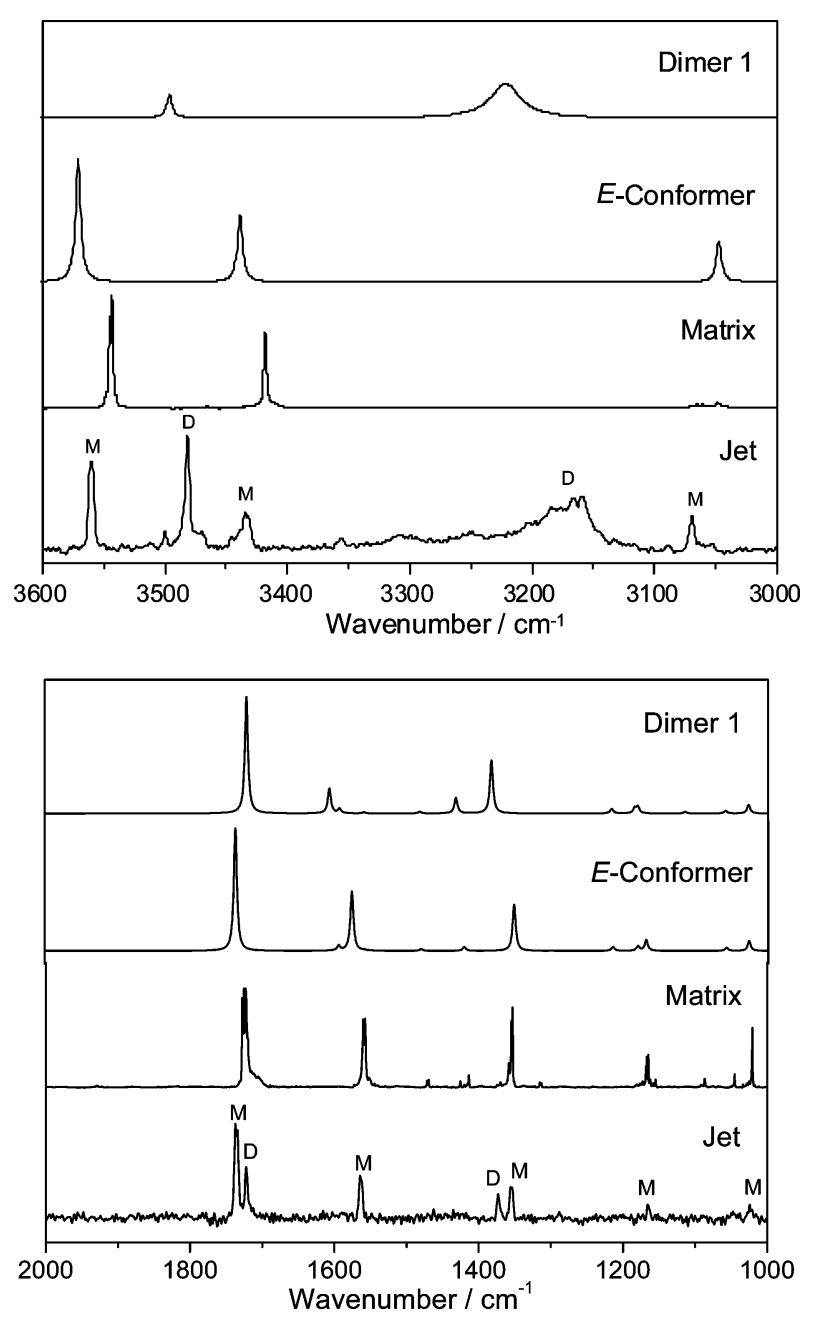

Figure 8. $\mathrm{N}-\mathrm{H}$ (top panel) and $\mathrm{C}=\mathrm{O}$ (bottom) stretching regions of the jet and argon matrix spectra of PZA, compared to scaled harmonic B3LYP calculations for the monomer ( $E$ conformer) and dimer (dimer 1). The jet spectrum was obtained for a sample heated to $140{ }^{\circ} \mathrm{C}$ and then expanded in a 1.4 bar He jet. The calculated spectra were simulated using Lorentzians with full width at half-maximum of $5 \mathrm{~cm}^{-1}$ for all bands except that ascribed to the $\mathrm{H}$-bonded $\mathrm{N}-\mathrm{H}$ stretching band of the dimer, which was approximated by a feature with a full width at half-maximum of $44 \mathrm{~cm}^{-1}$. The wavenumbers were scaled by 0.960 in the high frequency range and by 0.988 below $1800 \mathrm{~cm}^{-1}$. Note that in the different spectra the intensity scales are different (in each spectral region, each spectrum was normalized to the corresponding most intense band) so that comparison of intensities shown in the figure is only meaningful within a spectrum and the same spectral region.

nitrogen for structures close to this transition state, in order to minimize steric repulsion. For the minimum energy conformations, however, the pyramidalization angle assumes relatively small values, demonstrating the importance in these structures of the mesomerism within the amide group and, as already stressed before, also the prevalence of the H-bond-like interactions in the global minimum.

Matrix Isolation Infrared Spectra. Both $E$ and $Z$ conformers of PZA have 36 fundamental vibrations, all infrared active. Tables S2-S4 in the Supporting Information provide the calculated IR spectra and the results of the normal coordinate analysis undertaken for the two conformers. The spectra are depicted in Figure S1 in the Supporting Information.

Figure 5 shows the infrared spectra of PZA isolated in argon $(10 \mathrm{~K})$ and xenon $(20 \mathrm{~K})$ matrices and compares these spectra with those theoretically obtained for conformer $E$, whose population at the temperature used to sublimate PZA $\left(40{ }^{\circ} \mathrm{C}\right)$ could be estimated from the predicted relative energies of the conformers (and corresponding degeneracy) as being $>99.997 \%$. In addition, note that both the high relative energy of conformer $Z$ and the low energy barrier separating this form from the most stable conformer contribute to make the $Z$ form unimportant in practical terms for the analysis of the matrix isolation spectra. Indeed, with such a low energy barrier for $Z \rightarrow E$ conversion, the residual amount of $Z$ molecules existing in the gas phase prior to deposition can be expected to rapidly convert to the most stable form during deposition of the matrix. ${ }^{43-47}$

Because of the excellent agreement between the theoretical and experimental spectra (Figure 5), the general assignment of the experimental bands was straightforward (Table 2). Interestingly, the detailed analysis of the experimental spectra revealed that PZA molecules occupy three main matrix sites in the argon matrix, with most of the bands appearing split into triplets. The annealing experiments showed that one of these sites is considerably more stable than the others, with the molecules occupying the less stable sites being more prone to aggregation upon warming of the matrix than those in the most stable one. Figure 6 shows the changes in the $\mathrm{N}-\mathrm{H}$ asymmetric and $\mathrm{C}=\mathrm{O}$ stretching regions of the spectrum of PZA as a result of annealing. In the first spectral region, three bands are observed, corresponding to the three matrix sites. On the other hand, in the $\mathrm{C}=\mathrm{O}$ stretching region, one can observe six bands, with two per matrix site. The splitting observed for each site is tentatively ascribable to a Fermi resonance interaction involving the carbonyl stretching mode and an almost harmonic first overtone of a $\gamma(\mathrm{C}-\mathrm{H})$ ring rocking mode, whose fundamental vibration is observed in the $865-860 \mathrm{~cm}^{-1}$ region. The coupling matrix element is on the order of $1 \mathrm{~cm}^{-1}$, at least for the most stable site. It can be clearly seen in Figure 6 that, upon increasing the temperature of the matrix, the bands associated with the less stable sites (-) start losing intensity in favor of those associated with the most stable site $(+)$. This result shows that matrix reorganization starts to take place, leading to conversion of the less stable matrix sites into the most stable one. Simultaneously, aggregation of PZA starts to occur, as can be noticed by the growth of the broad complex band between 1715 and $1660 \mathrm{~cm}^{-1}$. At $36 \mathrm{~K}$, the bands related to the less stable sites have almost disappeared, whereas those related to the most stable site still continue increasing their intensity in spite of aggregation being already quite significant. At $39 \mathrm{~K}$, the bands of the most stable matrix site also start to decrease and those corresponding to aggregates already clearly dominate the spectrum. Note also that there is a good correspondence of the bands in the $\mathrm{N}-\mathrm{H}$ asymmetric and $\mathrm{C}=\mathrm{O}$ stretching regions, with the frequency order $(-)(+)(-)$ observed in the $\mathrm{N}-\mathrm{H}$ stretching region being the same as that observed in the $\mathrm{C}=\mathrm{O}$ stretching region, $(-)(-)(+)(+)(-)(-)$. This correspondence can be correlated with the relative importance of the H-bondlike interactions in the molecules occupying the different matrix sites; the stronger the interaction, the lower the frequency of the associated vibrations.

In the xenon matrix, PZA molecules also occupy different matrix sites, as shown by observation of multiplet bands ascribable to several skeletal and ring modes (e.g., bands at $1028 / 1023 / 1022 / 1020 / 1019$ or $931 / 927 / 923 \mathrm{~cm}^{-1}$, among other cases; see Table 2). However, the different local environments in the xenon matrix seem to have very similar stabilities, since they were found to behave similarly upon annealing of the matrix. In addition, they also seem to affect in a similar way the H-bonding in the molecule, since for both $\mathrm{N}-\mathrm{H}$ and $\mathrm{C}=\mathrm{O}$ stretching modes (the ones that could be expected to be more 


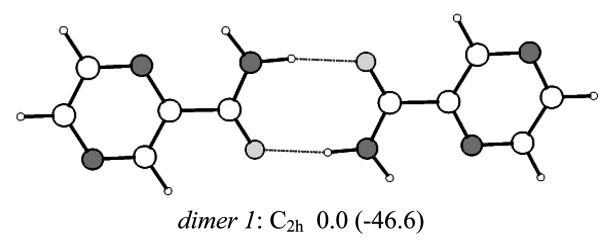

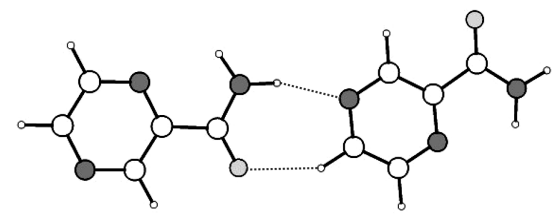

dimer 2: $\mathrm{C}_{\mathrm{S}} 20.3(-26.3)$

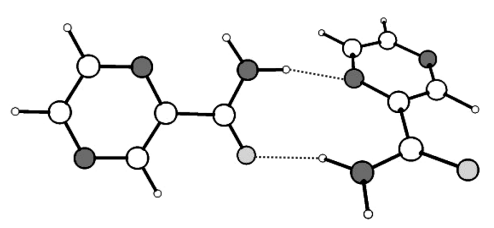

dimer 4: $\mathrm{C}_{1} 23.6(-23.0)$

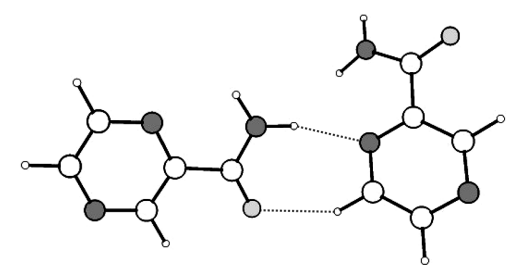

dimer 6: $\mathrm{C}_{1} 31.9(-14.7)$

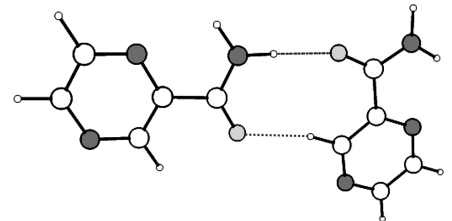

dimer 3: $\mathrm{C}_{1} 22.0(-24.6)$

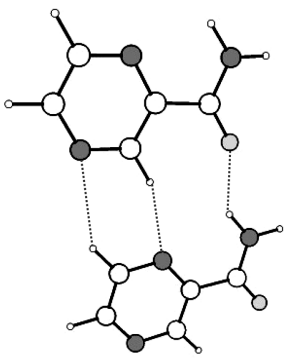

dimer 5: $\mathrm{C}_{\mathrm{S}} 29.0(-17.6)$

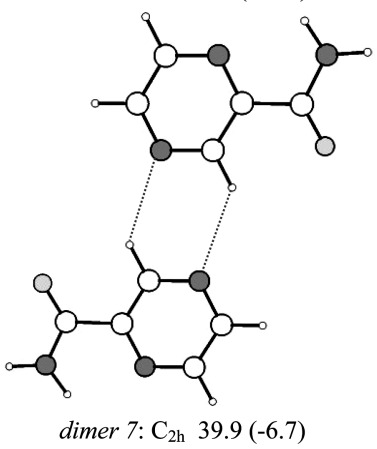

Figure 9. DFT(B3LYP)/6-311++G(d,p) calculated structures for the most stable dimers of PZA based on the most stable $E$ monomer. Relative energies of the dimers and dimerization energies [calculated as $E$ (dimer) $-2 E$ (monomer); in parentheses] are given in $\mathrm{kJ} \mathrm{mol}^{-1}$.

sensitive to that interaction) the observed spectral features do not show evidence of site splitting. Indeed, in the $\mathrm{N}-\mathrm{H}$ asymmetric stretching region, a single band is observed, whereas in the carbonyl stretching range the asymmetric profile of the observed feature only indicates the presence of the two overlapped bands associated with the above-mentioned Fermi doublet (see Figure 7).

On the other hand, the $\nu \mathrm{C}=\mathrm{O} / / 2 \gamma \mathrm{C}-\mathrm{H}$ Fermi interaction was found to be very similar in both argon and xenon matrices. From the observed splittings and relative component band intensities, the Sokolowska and Kecki model ${ }^{48}$ yields Fermi resonance coupling constants equal to $0.48 \mathrm{~cm}^{-1}$ in $\mathrm{Xe}$ and only slightly larger in $\operatorname{Ar}\left(0.87 \mathrm{~cm}^{-1}\right.$; average value for the three main observed matrix sites), which, in agreement with the close observed frequencies of the Fermi components, demonstrate the existence of only a reduced Fermi resonance coupling in both cases.

Infrared Spectra of the PZA Monomer and Dimer in a Supersonic Jet. For PZA in the jet expansion (using $\mathrm{He}$ as the carrier gas), the infrared spectrum was recorded in the 3600-3000 $\mathrm{cm}^{-1}$ (NH stretching) and $2000-1000 \mathrm{~cm}^{-1}$ (fingerprint) spectral regions (Figure 8). This spectrum shows features ascribable to the isolated monomer (labeled $\mathrm{M}$ ) as well as to the centrosymmetric dimer (labeled $\mathrm{D}$ ) bearing two $\mathrm{NH} \cdots \mathrm{O}=$ hydrogen bonds (dimer 1; Figure 9), whose energy was found to be considerably lower than those of any of the other dimeric structures, in agreement with its predominance as a structural unit in most of the polymorphs of the compound and also with results of relative stability of different isolated dimeric structures in similar compounds, for example, picolinamide (PA). ${ }^{40}$ The calculated IR spectra for the PZA monomer $(E)$ and dimer 1 are shown in Figure 8 for comparison with the experimental spectrum. From a comparison of experimental and B3LYP N-H, C=O, and $\mathrm{C}-\mathrm{N}$ stretching intensities, one may estimate a consistent monomer to dimer ratio of $\sim 4 \pm 1$. Figure 8 also shows the spectrum obtained for PZA in the as-deposited argon matrix $(10 \mathrm{~K})$, where the monomer is the only species significantly populated.

The signal-to-noise ratio in the jet spectra is relatively poor, allowing only for a confirmation of the strongest bands in the fingerprint region. However, the band at ca. $1720 \mathrm{~cm}^{-1}$ in the $\mathrm{C}=\mathrm{O}$ stretching region as well as the $\mathrm{N}-\mathrm{H}$ stretching region of the spectrum clearly reflect the extent of aggregation in the jet. The assignments for the spectrum of the compound in the jet are given in Table 3. The monomer bands are in good agreement with the matrix isolation data, with fairly systematic matrix-induced red-shifts $\left(\sim 15 \mathrm{~cm}^{-1}\right)$. The doublet structure of the monomer $\mathrm{C}=\mathrm{O}$ stretching mode is more likely due to rotational structure, implying that the postulated Fermi resonance in Ar is detuned in the isolated molecule. This is not surprising given the small coupling matrix element. 
TABLE 3: Observed Spectra of PZA in the Supersonic Jet (E Monomer and Dimer 1) and in Argon Matrix (E Monomer) in the 3600-3000 and $2000-1000 \mathrm{~cm}^{-1}$ Spectral Regions ${ }^{a}$

\begin{tabular}{|c|c|c|c|c|c|c|c|}
\hline \multirow[b]{2}{*}{$\begin{array}{l}\text { approximate } \\
\text { description }\end{array}$} & \multicolumn{2}{|c|}{ dimer 1} & \multicolumn{2}{|c|}{ monomer } & \multicolumn{2}{|c|}{ jet } & argon matrix \\
\hline & $\begin{array}{l}\text { calculated } \\
\text { wavenumber }\end{array}$ & $\begin{array}{l}\text { calculated } \\
\text { intensity }\end{array}$ & $\begin{array}{c}\text { calculated } \\
\text { wavenumber }\end{array}$ & $\begin{array}{l}\text { calculated } \\
\text { intensity }\end{array}$ & dimer & monomer & monomer \\
\hline$v\left(\mathrm{NH}_{2}\right)$ as & & & 3570.9 & 89.5 & & 3560 & $3548(-) / 3545(+) / 3543(-)$ \\
\hline$v(\mathrm{~N}-\mathrm{H})_{\text {free }}$ & 3495.7 & 406.7 & & & 3482 & & \\
\hline$v\left(\mathrm{NH}_{2}\right) \mathrm{s}$ & & & 3438.5 & 49.6 & & 3434 & 3418 \\
\hline$v(\mathrm{~N}-\mathrm{H})_{\mathrm{H}-\text { bond }}$ & 3221.9 & 2270.1 & & & 3166 & & \\
\hline$v(\mathrm{C}-\mathrm{H}) 1$ & & & 3070.8 & 0.2 & & 3069 & $3069(-) / 3065(+) / 3061(+)$ \\
\hline$\delta\left(\mathrm{NH}_{2}\right)$ & & & 1575.6 & 179.9 & & 1564 & $1560(-) / 1557(+)$ \\
\hline$v(\mathrm{C}-\mathrm{N})$ & 1382.3 & 344.2 & & & 1377 & & \\
\hline$v(\mathrm{C}-\mathrm{N})$ & & & 1351.3 & 140.4 & & 1356 & $1358 / 1354 / 1353 / 1350$ \\
\hline$v \operatorname{ring} 1$ & & & 1168.6 & 32.7 & & 1166 & $1168(-) / 1167(+) / 1165(-) / 1162(-)$ \\
\hline$\delta(\mathrm{C}-\mathrm{H}) 1$ & & & 1026.4 & 30.3 & & 1024 & $1028 / 1025 / 1021 / 1017$ \\
\hline
\end{tabular}

${ }^{a} \mathrm{~B} 3 \mathrm{LYP} / 6-311++\mathrm{G}(\mathrm{d}, \mathrm{p})$ theoretical vibrational data in the same spectral region is given for comparison. Wavenumbers (scaled by 0.960 in the high frequency range and 0.988 below $1800 \mathrm{~cm}^{-1}$ ) in $\mathrm{cm}^{-1}$, calculated intensities in $\mathrm{km} \mathrm{mol}{ }^{-1}$. $v$, bond stretching; $\delta$, bending; $\mathrm{s}$, symmetric; as, antisymmetric; $(+)$, most stable site; $(-)$, less stable site.

Figure 10 compares the supersonic jet spectra of PZA (bottom) and $\mathrm{PA}^{40}$ (top) in the $\mathrm{N}-\mathrm{H}$ stretching and fingerprint ranges. As can be noticed, in these spectral regions, the IR spectra of the two compounds are very similar, in particular the larger width of the bound $\mathrm{NH}$ band in both spectra when compared to that observed for nicotinamide ${ }^{40}$ is confirmed. However, a closer inspection reveals secondary bands in the vicinity of the dominant narrow free $\mathrm{NH}$ band as well as in between the free and the strongest bound dimer $\mathrm{NH}$ peak which are not so easy to detect in the noisier PA spectrum. These absorptions, which add up to about $10-20 \%$ of the dimer intensity, could have three reasons: (a) They may be due to Fermi resonance, as it is typical for strongly bound dimers. ${ }^{49}$ (b) They may be due to less stable dimers, as they are shown in Figure 9. The corresponding spectra may be found in the Supporting Information Figure S2. (c) They may be due to larger clusters, because the PZA dimer leaves more secondary interaction sites than the PA dimer.

Explanation (a) is unlikely for the free NH but may contribute to the width and spectral structure of the bound $\mathrm{NH}$ band, as postulated for $\mathrm{PA}^{40}$ and traced back to an efficient IVR (intramolecular vibrational energy redistribution) channel via the $\mathrm{NH} \cdots \mathrm{N}$ hydrogen bond. Explanation (b) is possible (see Figure S2 in the Supporting Information), but the quality of the spectra does not allow for a detailed assignment of these metastable dimer structures. Explanation (c) is also conceivable, but currently the limited S/N ratio does not justify a systematic exploration of the trimer potential energy hypersurface.

In any case, at least $80 \%$ of the spectral features in the jet can be attributed to the by far most stable dimer 1 , and the additional IVR channel compared to the nicotinamide dimer ${ }^{40}$ but not to the picolinamide dimer ${ }^{40}$ is confirmed. The substantial spectral broadening in two related compounds (picolinamide, pyrazinamide) but not in the third one (nicotinamide), which only differs in the position and coordination of the heterocyclic $\mathrm{N}$ atom, leaves little room for other explanations than intensified coupling of the $\mathrm{N}-\mathrm{H}$ stretching fundamentals to other vibrational modes.

Infrared Spectra of PZA in the Low Temperature Glass and Crystalline States. The top IR spectrum shown in Figure 11 [trace (a)] was obtained from the purchased PZA in a $\mathrm{KBr}$ pellet at room temperature. It is the characteristic spectrum of the $\alpha$ polymorph. ${ }^{31}$ A sample of this polymorph was then used
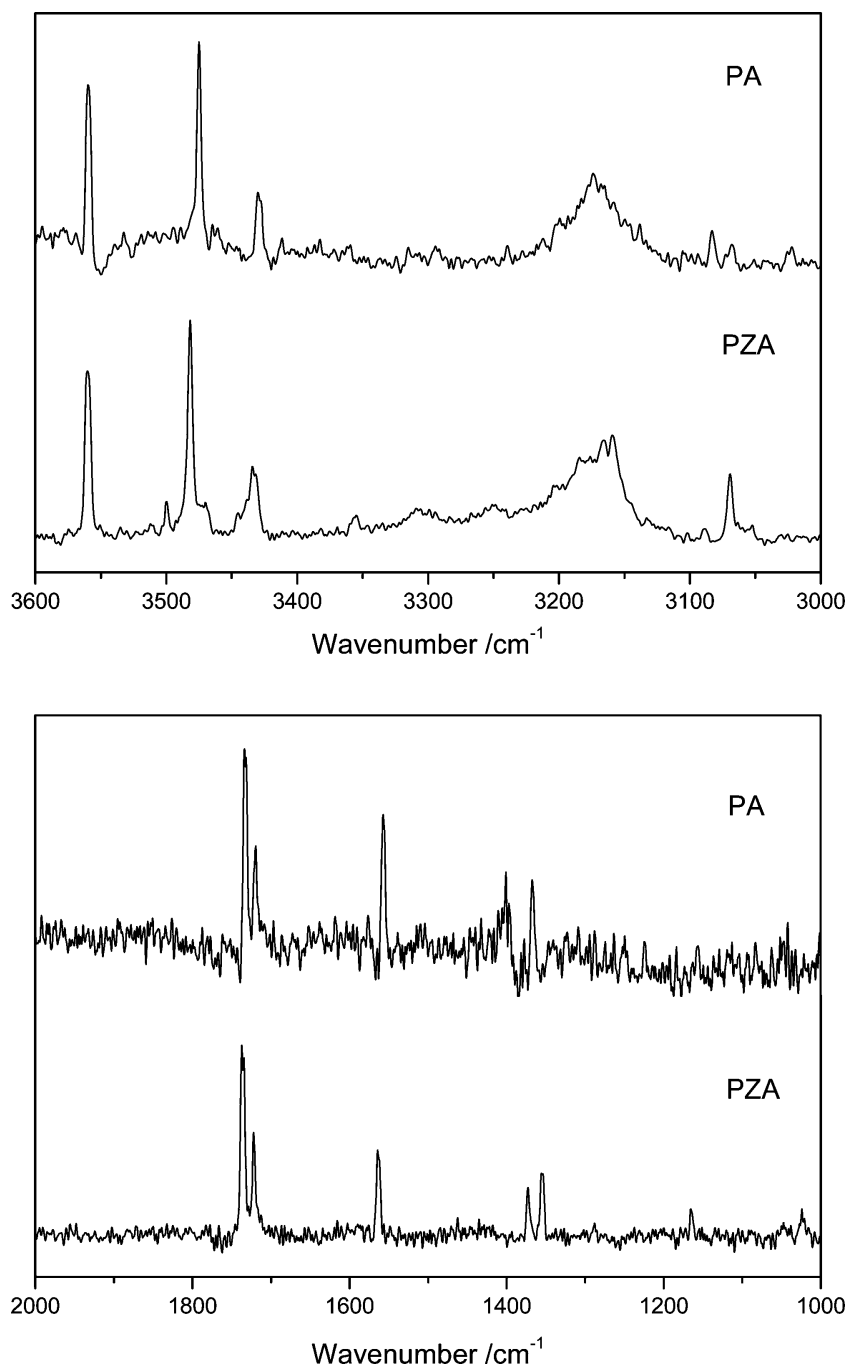

Figure 10. $\mathrm{N}-\mathrm{H}\left(3600-3000 \mathrm{~cm}^{-1}\right.$; top panel) and $\mathrm{C}=\mathrm{O}(2000-1000$ $\mathrm{cm}^{-1}$; bottom panel) stretching regions of the jet spectra of picolinamide (PA, sample at $100{ }^{\circ} \mathrm{C}$, expanded in $1.4 \mathrm{bar} \mathrm{He}$ ) and pyrazinamide (PZA, sample at $140{ }^{\circ} \mathrm{C}$, expanded in 1.4 bar He).

in our experiments. The film prepared from sublimating this sample and fast deposition of the obtained vapor onto the cryostat substrate kept at $10 \mathrm{~K}$ gave rise to the IR spectrum 


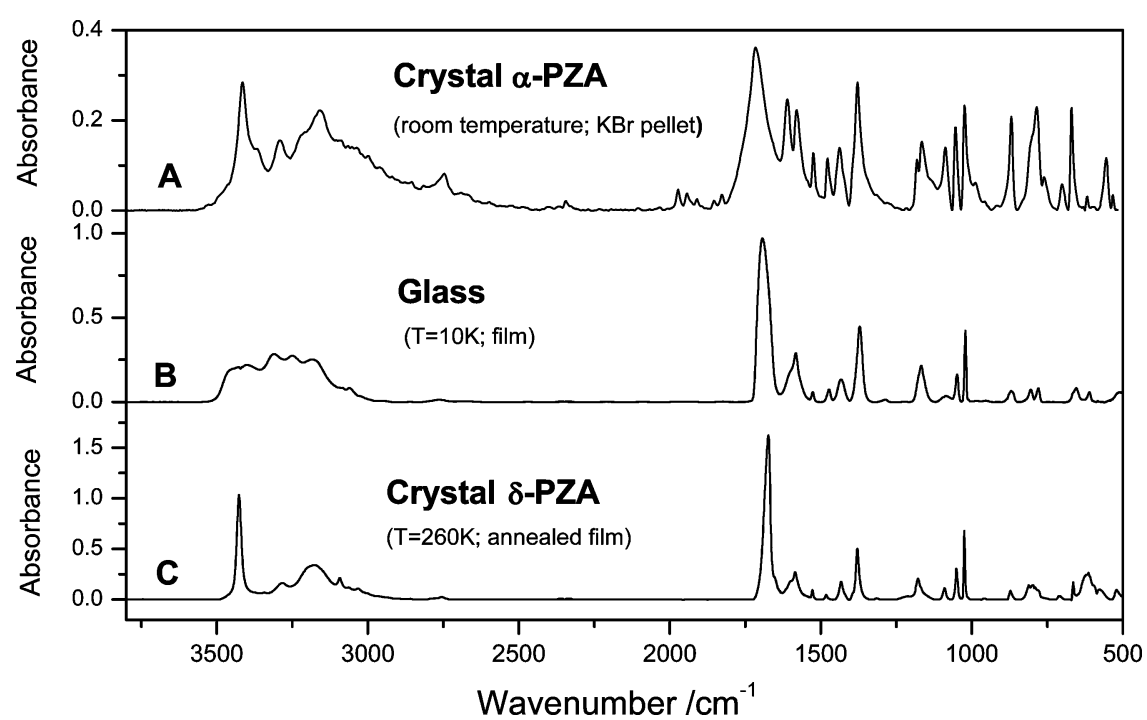

Figure 11. Infrared spectra $\left(3800-500 \mathrm{~cm}^{-1}\right)$ of solid PZA. From top to bottom: spectrum of the commercial sample ( $\alpha$ crystalline phase; KBr pellet; $25^{\circ} \mathrm{C}$ ), amorphous state obtained by fast deposition of the vapor of the compound onto the cold tip of the cryostat at $10 \mathrm{~K}$, and spectrum of the crystalline state resulting from warming the amorphous state up to $260 \mathrm{~K}$ ( $\delta$ phase).

TABLE 4: Observed Frequencies for the Neat PZA Solid in the Glassy State Resulting from Fast Deposition of the Vapor of the Compound onto the Cryostat's Cold Substrate at $10 \mathrm{~K}$, in the Crystalline State Resulting from Annealing of the Glassy Film at $260 \mathrm{~K}$, in the Room Temperature Crystalline Phase (in KBr Pellet) and Calculated Spectrum for Dimer 1, Using the DFT(B3LYP)/6-311++G(d,p) Level of Theory ${ }^{a}$

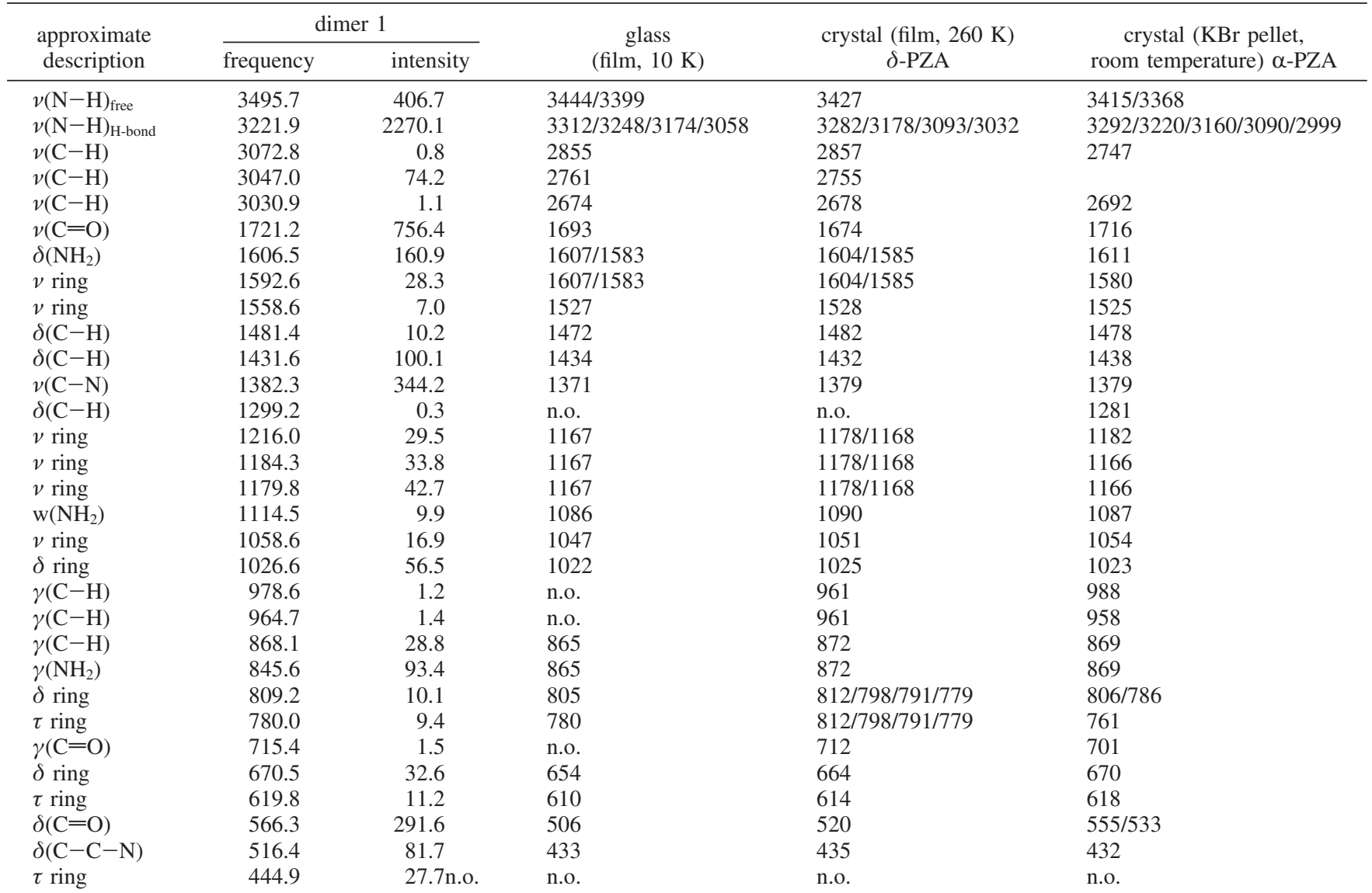

${ }^{a}$ Wavenumbers (scaled by 0.960 in the high frequency range and 0.988 below $1800 \mathrm{~cm}^{-1}$ ) in $\mathrm{cm}^{-1}$, calculated intensities in km mol ${ }^{-1} . v$, bond stretching; $\delta$, bending; s, symmetric; as, antisymmetric; n.o., not observed.

shown as trace (b) in Figure 11. It is a typical spectrum of an amorphous phase, with broad bands and, in particular, the absence of any well localized $\mathrm{N}-\mathrm{H}$ stretching band, which reveals the characteristic disordered $\mathrm{H}$-bonding network present in an amorphous phase. Upon warming the amorphous phase up to $260 \mathrm{~K}$, the spectrum changes, indicating crystallization of the sample. The obtained spectrum (Figure 11c) is the characteristic one of the $\delta$ modification of PZA. ${ }^{31}$ According to the thermodynamic data presented in ref 31 , the $\delta$ polymorph should correspond to the most stable crystalline phase of the 
compound, and it is interesting to observe that this was the one obtained directly from warming of the low temperature amorphous phase produced from the gas phase as described above. Investigations are now being performed in our laboratories on other compounds exhibiting polymorphism, in order to explore this approach to the production of a specific crystalline phase.

The proposed detailed assignments for the IR spectra of both $\alpha$ and $\delta$ crystalline polymorphs as well as for the amorphous state are given in Table 4 . This table also shows the calculated IR spectrum for the centrosymmetric dimer of PZA for comparison (calculated spectra for other low energy dimeric motifs are provided in the Supporting Information Figure S2).

\section{Conclusion}

Matrix isolation and supersonic jet techniques were applied to investigate monomers and dimers of pyrazinamide (PZA) using infrared spectroscopy. The assignment was assisted by calculations carried out at DFT and MP2 levels of theory. PZA was shown to possess two different energy minima, but only the most stable form is relevant in practical terms, due to the large energy difference between the two conformers $(>30 \mathrm{~kJ}$ $\mathrm{mol}^{-1}$ ) and the low energy barrier separating the higher energy form from the conformational ground state (less than $2 \mathrm{~kJ}$ $\mathrm{mol}^{-1}$ ). In consonance with the theoretical predictions, only the most stable conformer of PZA could be isolated in cryogenic rare gas matrices. In argon matrix, this species was found to occupy at least three distinct matrix sites, which possess considerably different stabilities. Full assignment of the spectra (in the $4000-400 \mathrm{~cm}^{-1}$ spectral range) of the matrix (argon and xenon) isolated PZA was undertaken, supported by the results of the theoretical calculations.

In a supersonic jet, besides the monomer, the most stable dimer of PZA (the centrosymmetric dimer bearing two $\mathrm{NH} \cdot \cdots \mathrm{O}=$ hydrogen bonds) could also be identified, together with minor contributions from metastable dimers or larger clusters. The characteristic fast IVR channel which was already observed for picolinamide was confirmed. It depends on a heterocyclic $\mathrm{N}$ atom in $\alpha$ position to the carboxamide group, which weakens the intermolecular $\mathrm{N}-\mathrm{H} \cdots \mathrm{O}=\mathrm{C}$ bond.

Finally, the IR spectra of the amorphous phase resulting from fast cooling of the vapor of the compound (initially in the $\alpha$ crystalline phase) onto the cold substrate of the cryostat $(10 \mathrm{~K})$ and of the crystalline phase resulting from warming the amorphous state were also recorded and interpreted. The obtained crystalline phase was found to be the thermodynamically most stable $\delta$ polymorph of PZA.

Acknowledgment. This work was supported by FCT (Project PTDC//QUI/71203/2006), CYTED Program: Network 108RT0362, and the DFG research training group 782 (www.pcgg.de). The authors also thank DAAD and FCT/GRICES for supporting the bilateral collaboration between the Portuguese and German groups. A.B. acknowledges FCT for the Ph.D. grant (SFRH/ BD/21543/2005). A.G.-Z. is member of the Research Career CONICET, Argentina.

Supporting Information Available: Figures S1 and S2 with B3LYP/6-311++G(d,p) calculated infrared spectra (4000-0 $\mathrm{cm}^{-1}$ region) for the two conformers of PZA and relevant PZA dimers, respectively. Table S1 with optimized structural parameters for the two confermers of PZA; Table S2 with definition of internal coordinates used in the normal coordinate calculations; Tables S3 and S4 with calculated IR spectra and results of the normal coordinate analysis for the two conformers of PZA. This material is available free of charge via the Internet at http://pubs.acs.org.

\section{References and Notes}

(1) Zhang, Y.; Mitchison, D. Int. J. Tuberculosis Lung Dis. 2003, 7, 6.

(2) Jasmer, R. M.; Daley, C. L Am. J. Respir. Crit. Care Med. 2003, 167,809 259.

(3) Gunasekaran, S.; Sailatha, E. Indian J. Pure Appl. Phys. 2009, 47,

(4) Borba, A.; Gomez-Zavaglia, A.; Fausto, R. J. Phys. Chem. A 2009, 113,9220 .

(5) Delgado, M. J. M.; Marquez, F.; Suero, M. I.; Marcos, J. I. Spectrosc. Lett. 1988, 21, 841.

(6) Kalkar, A. K.; Bhosekar, N. M.; Kshirsagar, S. T. Spectrochim. Acta, Part A 1989, 45, 635.

(7) Akyuz, S. J. Mol. Struct. 2003, 651, 541.

(8) Akyuz, S.; Akyuz, T. J. Inclusion Phenom. Macrocyclic Chem. 2004, 48,75 .

(9) Akyuz, S.; Andreeva, L.; Minceva-Sukarova, B.; Basar, G. J. Mol. Struct. 2007, 834, 399.

(10) Gunasekaran, S.; Ponnambalam, U.; Muthu, S.; Ponnusamy, S. Asian J. Chem. 2004, 16, 1513

(11) Wang, Y.; Li, Y. S.; Wu, J.; Zhang, Z. X.; An, D. Q. Spectrochim. Acta Part A 2000, 56, 2637.

(12) Barich, D. H.; Clawson, J. S.; Stueber, D.; Strohmeier, M.; Pugmire, R. J.; Grant, D. M. J. Phys. Chem. A 2002, 106, 11375.

(13) Cox, R. H.; Bothner-By, A. A. J. Phys. Chem. 1968, 72, 1646.

(14) Nangia, A.; Desiraju, G. Supramolecular Synthons and Pattern Recognition. In Design of Organic Solids; Topics in Current Chemistry; Weber, E. Ed.; Springer: Berlin/Heidelberg, 1998; Vol. 198, p 57.

(15) Becker, C.; Dressman, J. B.; Amidon, G. L.; Junginger, H. E.; Kopp, S.; Midha, K. K.; Shah, V. P.; Stavchansky, S.; Barends, D. M. J. Pharm. Sci. 2008, 97, 3709 . 693.

(16) Tamura, C.; Sasada, Y.; Kuwano, H. Acta Crystallogr. 1961, 14,

(17) Yoshida, S. Chem. Pharm. Bull. 1963, 11, 628.

(18) Takaki, Y.; Sasada, Y.; Watanabe, T. Bull. Chem. Soc. Jpn. 1959, $32,202$. 693.

(19) Takaki, Y.; Sasada, Y.; Watanabe, T. Acta Crystallogr. 1960, 13,

(20) Tiwari, R. K.; Deo, N.; Singh, T. P. J. Sci. Res. (Bhopal, India) 1980, $2,161$.

(21) Tiwari, R. K.; Patel, T. C.; Singh, T. P. Indian J. Phys. A 1982, 56,413 .

(22) Nangia, A.; Srinivasulu, A. Private communication, 2005.

(23) Ro, G.; Sorum, H. Acta Crystallogr., Sect. B: Struct. Sci. 1972, B $28,991$.

(24) Ro, G.; Sorum, H. Acta Crystallogr., Sect. B: Struct. Sci. 1972, B $28,1677$.

(25) Nakata, K.; Takaki, Y. Mem. Osaka Gakugei Univ. 1987, 36, 93.

(26) Tamura, C.; Kuwano, H. Nippon Kagaku Kaishi 1962, 83, 971.

(27) Takaki, Y. Mem. Osaka Gakugei Univ. 1965, B14, 39.

(28) Favila, A.; Gallo, M.; Glossman-Mitnik, D. J. Mol. Model. 2007, 13,505 .

(29) Cozar, O.; Chis, V.; David, L.; Baias, M. J. Optoelectron. Adv. Mater. 2006, 8, 164.

(30) Chis, V.; Pirnau, A.; Jurca, T.; Vasilescu, M.; Simon, S.; Cozar, O.; David, L. Chem. Phys. 2005, 316, 153.

(31) Castro, R. A. E.; Eusébio, M. E. S.; Castro, R. A. E.; Maria, T. M. R.; Évora, A. O. L.; Feiteira, J.; Silva, M. S.; Beja, A. M. M.; Canotilho, J.; Eusébio, E. M. S. Cryst. Growth Des., submitted for publication.

(32) Häber, T.; Schmitt, U.; Suhm, M. A. Phys. Chem. Chem. Phys. 1999, 1,5573 .

(33) Albrecht, M.; Rice, C. A.; Suhm, M. A. J. Phys. Chem. A 2008, 112,7530

(34) Frisch, M. J.; Trucks, G. W.; Schlegel, H. B.; Scuseria, G. E.; Robb, M. A.; Cheeseman, J. R.; Montgomery, J. J. A.; Vreven, T.; Kudin, K. N.; Burant, J. C.; Millam, J. M.; Iyengar, S. S.; Tomasi, J.; Barone, V.; Mennucci, B.; Cossi, M.; Scalmani, G.; Rega, N.; Petersson, G. A.; Nakatsuji, H.; Hada, M.; Ehara, M.; Toyota, K.; Fukuda, R.; Hasegawa, J.; Ishida, M.; Nakajima, T.; Honda, Y.; Kitao, O.; Nakai, H.; Klene, M.; Li, X.; Knox, J. E.; Hratchian, H. P.; Cross, J. B.; Bakken, V.; Adamo, C.; Jaramillo, J.; Gomperts, R.; Stratmann, R. E.; Yazyev, O.; Austin, A. J.; Cammi, R.; Pomelli, C.; Ochterski, J. W.; Ayala, P. Y.; Morokuma, K.; Voth, G. A.; Salvador, P.; Dannenberg, J. J.; Zakrzewski, V. G.; Dapprich, S.; Daniels, A. D.; Strain, M. C.; Farkas, O.; Malick, D. K.; Rabuck, A. D.; Raghavachari, K.; Foresman, J. B.; Ortiz, J. V.; Cui, Q.; Baboul, A. G.; Clifford, S.; Cioslowski, J.; Stefanov, B. B.; Liu, G.; Liashenko, A.; Piskorz, P.; Komaromi, I.; Martin, R. L.; Fox, D. J.; Keith, T.; Al-Laham, M. A.; Peng, C. Y.; Nanayakkara, A.; Challacombe, M.; Gill, P. M. W.; Johnson, 
B.; Chen, W.; Wong, M. W.; Gonzalez, C.; Pople, J. A. GAUSSIAN 03, revision B.01; Gaussian, Inc.: Wallingford, CT, 2004.

(35) Becke, A. D. Phys. Rev. A 1988, 38, 3098.

(36) Lee, C. T.; Yang, W. T.; Parr, R. G. Phys. Rev. B 1988, 37, 785.

(37) Vosko, S. H.; Wilk, L.; Nusair, M. Can. J. Phys. 1980, 58, 1200.

(38) Frisch, M. J.; Head-Gordon, M.; Pople, J. A. Chem. Phys. Lett. 1990, 166, 281

(39) Csaszar, P.; Pulay, P. J. Mol. Struct. 1984, 114, 31.

(40) Borba, A.; Albrecht, M.; Gomez-Zavaglia, A.; Lapinski, L.; Nowak, M. J.; Suhm, M. A.; Fausto, R. Phys. Chem. Chem. Phys. 2008, 10, 7010. (41) Schachtschneider, J. H.; Mortimer, F. S. Vibrational Analysis of Polyatomic Molecules. VI. FORTRAN IV Programs for Solving the Vibrational Secular Equation and for the Least-Squares Refinement of Force Constants; Project No. 31450. Structural Interpretation of Spectra; Shell Development Co.: Houston, TX, 1965.

(42) Peng, C.; Schlegel, H. Isr. J. Chem. 1994, 33, 449.
(43) Borba, A.; Gomez-Zavaglia, A.; Fausto, R. J. Mol. Struct. 2006, 794, 196.

(44) Jarmelo, S.; Lapinski, L.; Nowak, M. J.; Carey, P. R.; Fausto, R. J. Phys. Chem. A 2005, 109, 5689.

(45) Reva, I. D.; Ilieva, S. V.; Fausto, R. Phys. Chem. Chem. Phys. 2001, 3, 4235 .

(46) Reva, I. D.; Stepanian, S. G.; Adamowicz, L.; Fausto, R. Chem. Phys. Lett. 2003, 374, 631.

(47) Kaczor, A.; Reva, I. D.; Proniewicz, L. M.; Fausto, R. J. Phys. Chem. A 2006, 110, 2360.

(48) Sokolowska, A; Kecki, Z. J. Raman Spectrosc. 1986, 17, 29.

(49) Wassermann, T. N.; Rice, C. A.; Suhm, M. A.; Luckhaus, D. J. Chem. Phys. 2007, 127, 234309.

JP907466H 